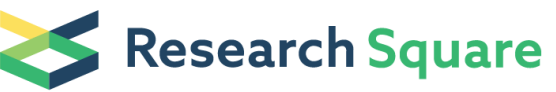 \\ Preprints are preliminary reports that have not undergone peer review. \\ They should not be considered conclusive, used to inform clinical practice, or referenced by the media as validated information.
}

\section{Impact of Screen Exposure on Pediatric Vernal Keratoconjunctivitis: a Survey During the COVID-19 Pandemic in Italy}

\section{Marzio Masini ( $\square$ marzio.masini@uniroma1.it)}

Sapienza University of Rome: Universita degli Studi di Roma La Sapienza https://orcid.org/0000-00027291-4202

\section{Giulia Brindisi}

Sapienza University of Rome: Universita degli Studi di Roma La Sapienza

\section{Mattia Giovannini}

Children Hospital Meyer: Azienda Ospedaliero Universitaria Meyer

\section{Elia Pignataro}

Sapienza University of Rome: Universita degli Studi di Roma La Sapienza

\section{Laura Di Grande}

Children Hospital Meyer: Azienda Ospedaliero Universitaria Meyer

\section{Cinzia De Libero}

Children Hospital Meyer: Azienda Ospedaliero Universitaria Meyer

\section{Francesca Mori}

Children Hospital Meyer: Azienda Ospedaliero Universitaria Meyer

\section{Roberto Caputo}

Children Hospital Meyer: Azienda Ospedaliero Universitaria Meyer

\section{Annamaria Zicari}

Sapienza University of Rome: Universita degli Studi di Roma La Sapienza

\section{Research}

Keywords: Vernal keratoconjunctivitis (VKC), children, SARS-CoV-2, COVID-19, lockdown, survey, screens

Posted Date: September 16th, 2021

DOI: https://doi.org/10.21203/rs.3.rs-877878/v1

License: (c) (1) This work is licensed under a Creative Commons Attribution 4.0 International License. Read Full License 
Version of Record: A version of this preprint was published at Italian Journal of Pediatrics on May 14th, 2022. See the published version at https://doi.org/10.1186/s13052-022-01253-2. 


\section{Abstract \\ Background}

SARS-CoV-2 outbreak pushed the Italian government to start a strict lockdown, replacing school attendance with long-distance learning. This caused reduced exposure to sunlight but increased exposure to screens. Vernal keratoconjunctivitis (VKC) is a chronic inflammatory ocular condition in which exposure to light plays a cardinal role. We conducted an online survey to evaluate the impact of screen exposure in children with VKC during the lockdown.

\section{Methods}

We performed a survey-based observational study, asking patients followed at the Allergology of Meyer Children's University Hospital in Florence and of Policlinico Umberto I in Rome to provide grading on 6 subjective ocular clinical manifestations presented during the lockdown and to give an estimate of the hours/day of screen exposure.

\section{Results}

Mean scores of signs and symptoms increased homogeneously when studying patients exposed to longer screen time. When comparing scores collected in 2019 versus 2020 , there was not a significant reduction in clinical manifestations, although the situation differed between the two centres due to geographical differences in sunlight exposure.

\section{Conclusion}

During the lockdown, there was a reduction of sunlight exposure but conversely an increase in the time spent in front of screens that correlated with the worsening of VKC signs symptoms in direct proportion to the hours/day of screen exposure. Our results also showed a statistically significant difference in the relative impact of long-distance learning on VKC clinical manifestations in the different Italian regions.

\section{Background}

In March 2020, a disease caused by the novel coronavirus SARS-CoV-2 was declared a pandemic by the World Health Organization with a rapid spread from China all over the world $(1,2)$. Italy is one of the hardest-hit countries with a total of 4.020 .139 confirmed cases and 119.594 reported deaths at the time of writing (3).

SARS-CoV2 causes a broad spectrum of clinical manifestations, including fever, anosmia, dry cough, dyspnoea, fatigue and, in critical cases, severe acute respiratory syndrome with intensive care 
hospitalization $(4,5)$. However, COVID-19 is less common in children, with most cases being mild and usually not requiring hospitalization (6). Governments in Italy and other countries announced strict lockdowns to contain the viral spread and flatten the contagion curve. In Italy, this period lasted from the 11th of March 2020 to the 3rd of June 2020 with the obligation to stay at home except for medical reasons and other urgent needs (7). So, many patients followed as outpatients were followed up by phone or emails (8).

VKC is a rare (9) chronic conjunctivitis that affects children and usually resolves in puberty. Typical VKC signs and symptoms, some shared with allergic conjunctivitis (AC), include photophobia, redness, itching and tearing, for which the drugs commonly used in AC, such as antihistamines, are usually ineffective except in initial and mild forms.

Concerning VKC aetiology, many hypotheses have been made, but the actual mechanism supporting the chronic inflammation in ocular conjunctiva remains still debated. Besides the autoimmune and allergic aetiology, a recent and intriguing hypothesis considered the role of oxidative stress in keeping chronic conjunctival inflammation active (10). In VKC, despite it being initially considered an IgE-mediated disease with a T helper 2 (Th2) inflammatory response, skin prick tests (SPT) and serum specific lgE levels (slgE) are positive in about $30-50 \%$ of the cases. Various cytokines, such as interleukin (IL)-1, IL-4, IL-5, and IL-13, keep the ocular inflammation active. The finding of systemic pro-inflammatory markers demonstrated that this chronic inflammation is not only local but also systemic with crosstalk between Th2 and Th1 mediated responses (10).

In the management of VKC, it is essential to start early treatment with immunosuppressant agents like topical corticosteroids. Unfortunately, the long-term use of topical corticosteroids is frequently complicated by cataract and glaucoma. Therefore, patients need topical immunosuppressant therapy like cyclosporine A or tacrolimus eye drops (11) to reduce ocular inflammation and prevent long-term ocular damage (12-16).

In Italy, during the lockdown, a widespread closure of schools was issued, marking the beginning of longdistance learning. Children and teenagers experienced for the first-time remote teaching at home, with the use of smartphones, computers and tablets for many hours/day, resulting in several physical and psychological consequences (17). Light and especially sunlight plays the primary role in worsening VKC clinical manifestations. We would have expected that the reduced sunlight exposure due to lockdown would have greatly benefitted our patients. On the contrary, in our clinical practice, we noticed that our patients had similar or worse signs and symptoms than the previous years.

To the best of our knowledge, no studies reported data on clinical manifestations in pediatric VKC during the lockdown. Moreover, data on the effects of using digital screens on VKC signs and symptoms are scarce and usually hard to quantify. Long-distance learning on a national scale represented a unique opportunity to explore the effects of regular and well-quantifiable exposure to screens on many paediatric patients with VKC. Thus, we conducted an online survey to evaluate the impact of this exposure in children with VKC patients during the lockdown. 


\section{Materials And Methods:}

We performed a survey-based observational study enrolling children with VKC, aged 5 to 17 years, from the Allergy Unit of Meyer Children's University Hospital in Florence and from the Pediatric Allergology Clinic of the Policlinico Umberto I in Rome. Inclusion criteria were the following: diagnosis of VKC made at least one year before the enrolment based on the clinical history and ocular examination with signs and symptoms of VKC carried out by an expert physician. Exclusion criteria were the presence of other chronic ocular or systemic diseases.

Regarding clinical grading/history, each patient/patient's parent was asked to complete an online questionnaire focused on ocular signs and symptoms (itching, photophobia, tearing, foreign body sensation and burning sensation), which were scored as previously reported $(14,18)$, referring to the period March - June 2020 (national lockdown). Each variable was graded: $0=$ no symptoms; $1=$ mild symptoms; 2 = moderate symptoms; 3 = severe symptoms. Each patient/parent was also asked to give an estimate of the amount of time spent in front of a screen (e.g., tablet, computer) due to long-distance learning, and patients were divided into 4 groups: less than 2 hours/day, 2-4 hours/day, 4-6 hours/day, and more than 6 hours/day of screen exposure. As accessory data, we asked the patients/patients' parents to grade the same clinical manifestations but referring to the same period (March - June) of the previous year (2019) to get an idea of the change in the symptoms between 2019 and 2020. Maintenance therapy was also registered, as well as demographic characteristics and the presence of atopic and nonatopic comorbidities.

All data were analysed with the use of IBM SPSS version 26 statistical software (IBM, Armonk, New York, United States of America). The Student t-test for paired samples was used for the comparison of mean scores between different times of exposure. $P$ values less than 0.05 were considered statistically significative.

\section{Results}

A total of 161 VKC children were recruited into the study: 98 patients $(60.87 \%)$ from the Allergy Unit of the Meyer Children's University Hospital (Florence) and 63 patients (39.13\%) from the Pediatric Allergology Clinic of Policlinico Umberto I (Rome) with a diagnosis of VKC. The mean age was $10.9 \pm$ standard deviation (SD) 2.97 years (range $5-17$ years), $M: F=3: 1$. Age and sex did not differ statistically between the two centres (age T test p-value: 0.877; sex chi-squared test p-value: 0.892). In detail, the mean age at onset of VKC was $7.05 \pm$ SD 2.73 years. Of these patients, $47.2 \%$ reported 1 or more allergic comorbidities; 35 (22\%) reported rhinitis, $24(14.9 \%)$ asthma, 38 (23.6\%) atopic dermatitis, $8(4.96 \%)$ food allergy. As previously mentioned, we divided our patients by the average number of hours of exposition to screens due to long-distance learning, forming 4 "Exposure groups": less than 2 hours/day (50 patients, or $31 \%$ of total), $2-4$ hours/day (63 patients, $39 \%$ of total), $4-6$ hours/day (28 patients, $17.39 \%$ of total) and more than 6 hours/day (12 patients, $7.5 \%$ of total). The "Less than 2 hours/day" exposure group was not included in this part of the study since that kind of exposure to screens was not deemed significant. 
Table 1

characteristics of the study population

\begin{tabular}{|ll|}
\hline Characteristics $(\mathbf{n}=\mathbf{1 6 1})$ & \\
\hline Age (years) & $10.9 \pm 2,97$ \\
\hline Females & $7.05 \pm 2.73$ \\
\hline Age of onset (years) & $76(47.2 \%)$ \\
\hline Patients with atopic comorbidities - total: & $35(22 \%)$ \\
\hline Rhinitis & $24(14.9 \%)$ \\
\hline Asthma & $38(23.6 \%)$ \\
\hline Atopic dermatitis & $8(4.96 \%)$ \\
\hline Food Allergy & \\
\hline Exposure groups: & $50(31 \%)$ \\
\hline $0-2$ hours/day & $63(39 \%)$ \\
\hline $2-4$ hours/day & $28(17.39 \%)$ \\
\hline $4-6$ hours/day & $12(7.5 \%)$ \\
\hline More than 6 hours/day & \\
\hline Data were represented as $N(\%)$ or mean \pm standard deviation \\
\hline
\end{tabular}


Table 2

mean symptoms scores for children exposed to screens, divided according to exposure groups

\begin{tabular}{|lllllll|}
\hline & & Itching & Photophobia & Tearing & $\begin{array}{l}\text { Foreign Body } \\
\text { Sensation }\end{array}$ & Burning \\
\hline $\begin{array}{l}\text { March-June 2020: 2- } \\
\text { 4h/day }(\mathrm{n}=63)\end{array}$ & Mean & 1,1111 & 1,1269 & 0,9206 & 0,9047 & 1,1269 \\
\cline { 2 - 7 } & SD & 0,9000 & 0,9586 & 0,9384 & 0,9624 & 1,0394 \\
\cline { 2 - 5 } & Total & 5,1904 & & & & \\
$\begin{array}{l}\text { March-June 2020: 4- } \\
\text { 6h/day }(\mathrm{n}=\text { 28) }\end{array}$ & Mean & 1,0714 & 1,3571 & 1,2143 & 0,9643 & 1,1785 \\
& SD & 0,8997 & 1,0959 & 0,7868 & 0,9222 & 0,9833 \\
\hline $\begin{array}{l}\text { March-June 2020: } \\
>\text { 6h/day }(\mathrm{n}=12)\end{array}$ & Total & 5,7857 & & & & \\
& Mean & 1,4166 & 1,3333 & 1,4166 & 1,4166 & 1,5833 \\
\hline SD: Standard Deviation & SD & 0,7929 & 1,1547 & 0,9003 & 0,9962 & 0,5149 \\
\hline
\end{tabular}

A table showing Pearson correlation coefficients between symptoms scores and screen exposure and the graph showing trends in clinical manifestations scores can be seen below. (Table 2, Fig. 1):

Table 3

Pearson correlation coefficient between screen exposure and symptoms severity

\begin{tabular}{|ll|}
\hline & Screen Exposure \\
\hline Total & 0,9938 \\
\hline Itching & 0,8087 \\
\hline Photophobia & 0,8151 \\
\hline Tearing & 0,9944 \\
\hline Foreign Body sensation & 0,9142 \\
\hline Burning & 0,9130 \\
\hline
\end{tabular}

We found mean scores of signs and symptoms to homogeneously increase when studying patients exposed to progressively longer screen times. This was particularly true when comparing burning, foreign 
body sensation and tearing, which saw a steady increase from the 2-4 hours/day to the more than 6 hours/day group.

Itching was found to be stable between the 2-4 and 4-6h/day groups, and photophobia seemed to be slightly less pronounced in the "more than 6 hours/day" group when compared to the "4-6h/day" group. However, the T-test between those two groups was not significant $(p=0.423)$, so we can interpret this finding as photophobia not being statistically different between the 4-6h/day and the more than 6 hours of screen time/day populations.

Nonetheless, when evaluating each clinical manifestation, we saw a significant increase in severity when comparing the group with the least exposure to the group with the most exposure. However, due to the low numbers of patients in the More than 6 hours/day group, the differences were not statistically significant for itching and photophobia scores, as seen in Table 3.

Table 4

student T-tests comparing symptoms of the " $2-4 \mathrm{~h} /$ day" and the "more than $6 \mathrm{~h} /$ day" exposure groups

\begin{tabular}{|llllll|}
\hline & Itching & Photophobia & Tearing & $\begin{array}{l}\text { Foreign Body } \\
\text { sensation }\end{array}$ & Burning \\
\hline $\begin{array}{l}\text { T-test p-values 2-4h vs }> \\
\text { 6h/day }\end{array}$ & 0,1240 & 0,2848 & 0,0508 & 0,0453 & 0,0140 \\
\hline T Test: Student T test & & & & & \\
\hline
\end{tabular}

Moreover, we asked parents to estimate their children's eye signs and symptoms looking back at the same period we explored in the previous paragraphs (March-June) of the previous year (2019), as to get an approximate idea of how the lockdown impacted VKC clinical manifestations, with a positive influence (less sunlight exposure) or negative influence (more digital screens exposure).

Table 5

Mean score comparison 2019 vs 2020 - pooled results (Florence + Rome)

\begin{tabular}{|llllll|}
\hline & Itching & Photophobia & Tearing & Foreign Body Sensation & Burning \\
\hline Mean 2019 & 1,3478 & 1,4968 & 1,2298 & 1,2670 & 1,3478 \\
\hline SD 2019 & 0,9438 & 0,9754 & 0,9370 & 0,9985 & 0,9569 \\
\hline Mean 2020 & 1,2360 & 1,3229 & 1,1428 & 1,0683 & 1,2484 \\
\hline SD 2020 & 0,9186 & 1,0037 & 0,9209 & 1,0007 & 0,9939 \\
\hline T Test p-values & 0,0947 & 0,0067 & 0,1449 & 0,0040 & 0,1446 \\
\hline \multicolumn{5}{|l}{ SD: Standard deviation. T Test: Student T test } \\
\hline
\end{tabular}


Photophobia and foreign body sensation showed a decrease between the same periods of 2019 and 2020 , with a statistically significant difference (T-test p-values respectively 0.006 and 0.004 ); all the other signs and symptoms were not reported as significantly different (Table 4). When evaluating separately the scores reported by the two centres, different data were demonstrated (Table 5).

Table 6

Mean scores comparison 2019 vs 2020 - individual results

\begin{tabular}{|c|c|c|c|c|c|c|}
\hline & & Itching & Photophobia & Tearing & $\begin{array}{l}\text { Foreign Body } \\
\text { Sensation }\end{array}$ & Burning \\
\hline \multirow[t]{3}{*}{ Florence } & $\begin{array}{l}\text { Mean } \\
2019 \text { (SD) }\end{array}$ & $\begin{array}{l}1,2449( \pm \\
0,897)\end{array}$ & $\begin{array}{l}1,3673( \pm \\
0,901)\end{array}$ & $\begin{array}{l}1,2143( \pm \\
0,864)\end{array}$ & $\begin{array}{l}1,2041( \pm \\
0,984)\end{array}$ & $\begin{array}{l}1,2347( \pm \\
0,928)\end{array}$ \\
\hline & $\begin{array}{l}\text { Mean } \\
2020 \text { (SD) }\end{array}$ & $\begin{array}{l}1,2551( \pm \\
0,945)\end{array}$ & $\begin{array}{l}1,3775( \pm \\
0,969)\end{array}$ & $\begin{array}{l}1,2551( \pm \\
0,889)\end{array}$ & $\begin{array}{l}1,1734( \pm \\
1,016)\end{array}$ & $\begin{array}{l}1,3367( \pm \\
0,963)\end{array}$ \\
\hline & $\begin{array}{l}T \text { Test } p- \\
\text { values }\end{array}$ & 0,1973 & 0,2944 & 0,6942 & 0,2507 & 0,00003 \\
\hline \multirow[t]{3}{*}{ Rome } & $\begin{array}{l}\text { Mean } \\
2019 \text { (SD) }\end{array}$ & $\begin{array}{l}1,5079( \pm \\
0,998)\end{array}$ & $\begin{array}{l}1,6984( \pm \\
1,057)\end{array}$ & $\begin{array}{l}1,2539 \\
1,047)\end{array}$ & $1,3650( \pm 1,02)$ & $\begin{array}{l}1,5238( \pm \\
0,981)\end{array}$ \\
\hline & $\begin{array}{l}\text { Mean } \\
2020 \text { (SD) }\end{array}$ & $\begin{array}{l}1,2063( \pm \\
0,883)\end{array}$ & $\begin{array}{l}1,2381 \\
1,058)\end{array}$ & $\begin{array}{l}0,9682( \pm \\
0,95)\end{array}$ & $\begin{array}{l}0,9047( \pm \\
0,962)\end{array}$ & $\begin{array}{l}1,1111( \pm \\
1,033)\end{array}$ \\
\hline & $\begin{array}{l}\text { T Test } p- \\
\text { values }\end{array}$ & 0,0190 & $3,28 E-06$ & 0,0014 & 7,12E-05 & 0,0003 \\
\hline
\end{tabular}

Children referring to Meyer Children's University Hospital reported a slight worsening of their signs/ symptoms during the lockdown, despite being exposed to long-distance learning with a similar distribution to their peers of Policlinico Umberto I (mean screen exposure - Policlinico Umberto I: 3.06 h/day; Meyer: $3 \mathrm{~h} /$ day, T-test p-value: 1). However, the differences were not statistically significant except when considering burning sensation scores.

Instead, children from the latter centre reported a statistically significant reduction in the severity of signs and symptoms during the lockdown period compared with the same period of the previous year.

It is important to acknowledge that the two Centres follow patients from different regions of Italy, with Meyer's Children's Hospital gathering patients mostly from central and northern regions: average latitude of places of residence of patients from the Tuscan centre was $43.712^{\circ}\left(S D \pm 2.06^{\circ}\right)$, while patients from the Roman centre were from cities, on average, from southern regions, averaging a latitude of $41.910^{\circ}$ $\left(S D \pm 0.211^{\circ}\right)$. The difference was statistically significative $\left(T\right.$ test $p$ value $\left.3.597 \times 10^{-7}\right)$. 


\section{Discussion}

To the best of our knowledge, this is the first survey that evaluated the impact of exposure to screens during the COVID-19 lockdown on VKC clinical manifestations in a pediatric population.

The management of several diseases during home quarantine has changed and adapted to this critical period where the priority of the hospitals has been the management of emergencies. For this reason, the use of surveys has been useful to understand the impacts and consequences of home quarantine on signs and symptoms in several pathologies, as well as VKC in our case.

VKC is not, like allergies, a risk factor for the susceptibility to SARS CoV- 2 infections, and neither is their treatment; for this reason, the standard treatment should be continued in VKC as well as in allergic pathologies (19-21). VKC is a chronic inflammatory ocular pathology in which photophobia is one of the most troublesome clinical manifestation, together with foreign body sensation, itching and tearing that are also present in $\mathrm{AC}(10)$.

During the lockdown, there was a reduction of the exposure to sunlight, but conversely, the time spent in front of PCs, TVs and video games increased (22). During the lockdown, long-distance learning has been instituted for children over the age of 5 , using video-conference platforms. This had the drawback of exposing children and adolescents to a critical load of screen time. Indeed, some of our patients had to regularly sit in front of screens for 6 hours/day and more.

Establishing a controlled exposure to screens allowed us to evaluate more accurately than before the effect of different loads of light exposure from screens on a subset of children, as VKC patients, for whom light is a trigger of clinical manifestations.

Consistent with this situation, results of our study have shown a general trend of increase in VKC clinical manifestations, such as tearing, foreign body sensation and burning, when comparing the " $2-4 \mathrm{~h} /$ day" group to the "more than 6 hours/day" group. The T-test analysis showed a statistically significant difference between the group with the minimum exposure compared to the group with the most exposure ("more than 6 hours of screen time/day") to screens.

Instead, the symptom of itching was found to be stable between the 2-4 and 4-6h/day groups and the symptom photophobia was apparently less severe in the "more than 6 hours/day" group when compared to the "4-6h/day" group, but the statistical analysis found no statistical significance.

A strong Pearson correlation coefficient has shown a high correlation between screen exposure and all VKC symptoms, such as itching, photophobia, tearing, foreign body sensation, and burning.

Moreover, considering the comparison between 2020 and 2019 in the same period (March - June), only photophobia and foreign body sensation showed a decrease in 2020 in comparison with the previous year, with a statistically significant difference (T-test $p$-values respectively 0.006 and 0.004 ). In contrast, all other signs and symptoms were not found as significantly different. 
When considering Rome and Florence separately, the statistical analysis revealed further information. Referring to Policlinico Umberto I Hospital, we found a statistically significant reduction in the severity of symptoms during home quarantine in 2020 compared to the same period of the previous year. Instead, in Meyer Children's University Hospital patients, we have seen a mild worsening of VKC symptoms during the lockdown period in 2020 compared to the same period of 2019, but with poor statistical significance: only for the clinical manifestation of burning the difference between 2020 versus 2019 reached statistical significance.

These results could be explained by the different weather and latitudes of the two centres. Sunlight exposure is more abundant in southern regions, so patients referring to Policlinico Umberto I probably experienced a relative reduction of light exposure during the lockdown compared to the previous year, even considering the "Mandatory" screen light exposure required by long-distance learning. This might have played a role in the reported improvement in signs and symptoms by children referring to this centre. In northern regions, sunlight is less abundant, so the reduction in sunlight exposure is relatively less significant when compared to the increase in screen exposure, resulting in a slight worsening of VKC signs and symptoms.

In literature, several studies have been conducted considering allergic pathologies and in particular allergic conjunctivitis during lockdown $(1,20,23)$, but to the best of our knowledge, no studies are reporting VKC symptoms during it.

The study conducted by Walaa Al-Dairi et al. analysed the impact of lockdown on patients' quality of life with allergic conjunctivitis, and it was reported, unlike our results, that there was no important effect on the Quality of life of allergic conjunctivitis during the COVID-19 lockdown (24).

Leonardi et al., in accordance with the EAACI guidelines (25), provided indications in the management of seasonal (SAC) and perennial (PAC) allergic conjunctivitis, VKC and atopic keratoconjunctivitis (AKC), highlighting that the treatment options for SAC/PAC, VKC and AKC were still valid also during COVID-19 outbreak (26).

\section{Limitations}

This study presents some limitations; first of all, its nature, being based on an online-survey. Another one was using a non-standardised questionnaire (however, to the best of our knowledge, standardized questionnaires on this topic are not available). Selection bias should also be considered since people more interested in the SARS-CoV-2 outbreak may have been more likely to answer the survey. Moreover, our survey didn't focus on less quantifiable screen exposure, like videogames or smartphone use. Lastly, the sample size is relatively small. Thus, further studies with a larger sample size should be desirable in the future to shed light on this specific topic.

\section{Conclusions}


Screen exposure correlates with worsening of VKC clinical manifestations in proportion to the number of hours/day of exposure. The establishment of long-distance learning and the regular screen exposure prescribed by schools made it possible to carry out a dedicated investigation and ascertain this correlation. In Italy, during the lockdown, there was a reduction of the exposure to sunlight but conversely an increase in the time spent in front of screens. This could explain the general trend of increasing VKC signs and symptoms in our pediatric population. Therapy should be continued as well as the close monitoring of clinical manifestation in children with VKC partaking in long-distance learning.

\section{Declarations}

\section{Author contribution}

MM contributed to the conception and design of the study. MS, GB, LDG, RC, CDL, EP, FM and AMZ contributed to the acquisition of data. MM performed the statistical analysis of data. MM and GB contributed to the interpretation of the results and in drafting the manuscript. All authors revised and approved the final version of the manuscript.

\section{Data availability statement}

Due to the nature of this research, participants of this study did not agree for their data to be shared publicly, so supporting data is not available.

\section{Ethics approval and consent to participate}

Due to the nature of this study (anonymized questionnaire) ethics approval was not required.

\section{Consent for publication}

Not applicable

\section{Availability of data and materials}

The data that support the findings of this study are available on request from the corresponding author. The data are not publicly available due to privacy or ethical restrictions.

\section{Competing interests}

The authors declare that they have no conflict of interests to disclose in relation to this paper. 


\section{Funding}

This research did not receive any specific grant from funding agencies in the public, commercial, or nonprofit sectors.

\section{References}

1. Diaferio L, Parisi GF, Brindisi G, Indolfi C, Marchese G, Ghiglioni DG, et al. Cross-sectional survey on impact of paediatric COVID-19 among Italian paediatricians: Report from the SIAIP rhino-sinusitis and conjunctivitis committee. Italian Journal of Pediatrics [Internet]. 2020 Oct 6 [cited 2021 Apr 28];46(1):146. Available from: https://moh-it.pure.elsevier.com/en/publications/cross-sectionalsurvey-on-impact-of-paediatric-covid-19-among-ita-2.

2. Riggioni $C$, Comberiati $P$, Giovannini $M$, Agache I, Akdis M, Alves-Correia M, et al. A compendium answering 150 questions on COVID-19 and SARS-CoV-2 [Internet]. Vol. 75, Allergy: European Journal of Allergy and Clinical Immunology. Blackwell Publishing Ltd; 2020 [cited 2021 Jun 6]. p. 2503-41. Available from: https://pubmed.ncbi.nlm.nih.gov/32535955/.

3. Infografica web -. Dati della Sorveglianza integrata COVID-19 in Italia [Internet]. [cited 2021 May 12]. Available from: https://www.epicentro.iss.it/coronavirus/sars-cov-2-dashboard.

4. Parisi GF, Brindisi G, Indolfi C, Diaferio L, Marchese G, Ghiglioni DG, et al. Upper airway involvement in pediatric COVID-19. Pediatric Allergy and Immunology [Internet]. 2020 Nov 1 [cited 2021 Apr 28];31(S26):85-8. Available from: https://pubmed.ncbi.nlm.nih.gov/33236430/.

5. Gori A, Leone F, Loffredo L, Cinicola BL, Brindisi G, de Castro G, et al. COVID-19-Related Anosmia: The Olfactory Pathway Hypothesis and Early Intervention. Frontiers in Neurology [Internet]. 2020 Sep 10 [cited 2021 Apr 28];11. Available from: https://pubmed.ncbi.nlm.nih.gov/33013637/.

6. Chan JFW, Yuan S, Kok KH, To KKW, Chu H, Yang J, et al. A familial cluster of pneumonia associated with the 2019 novel coronavirus indicating person-to-person transmission: a study of a family cluster. The Lancet [Internet]. 2020 Feb 15 [cited 2021 Apr 28];395(10223):514-23. Available from: https://pubmed.ncbi.nlm.nih.gov/31986261/.

7. Orgilés M, Morales A, Delvecchio E, Mazzeschi C, Espada JP. Immediate Psychological Effects of the COVID-19 Quarantine in Youth From Italy and Spain. Frontiers in Psychology [Internet]. 2020 Nov 6 [cited 2021 Apr 28];11. Available from: https://pubmed.ncbi.nlm.nih.gov/33240167/.

8. Giovannini M, Lodi L, Sarti L, Guarnieri V, Barni S, Canessa C, et al. Pediatric Allergy and Immunology Practice During the COVID-19 Pandemic in Italy: Perspectives, Challenges, and Opportunities. Frontiers in Pediatrics [Internet]. 2020 Nov 23 [cited 2021 Jun 6];8. Available from: https://pubmed.ncbi.nlm.nih.gov/33330268/.

9. Mori F, Barni S, Saretta F, Castagnoli R, Arasi S, Mastrorilli C, et al. Epidemiology of rare allergic diseases in children. Pediatric Allergy and Immunology [Internet]. 2020 Nov 1 [cited 2021 Jun 6];31(S26):39-42. Available from: https://pubmed.ncbi.nlm.nih.gov/33236442/. 
10. Zicari AM, Brindisi G, de Castro G, Lollobrigida V, Nebbioso M, Duse M. Is oxidative stress involved in vernal keratoconjunctivitis? Results from a pilot study in children. Pediatric Allergy and Immunology [Internet]. 2020 Nov 1 [cited 2021 Apr 28];31(S26):52-6. Available from: https://pubmed.ncbi.nlm.nih.gov/33236421/.

11. Zhao M, He F, Yang Y, Lin W, Qiu W, Meng Q, et al. Therapeutic efficacy of tacrolimus in vernal keratoconjunctivitis: A meta-analysis of randomised controlled trials. European Journal of Hospital Pharmacy. BMJ Publishing Group; 2020.

12. Pucci N, Caputo R, di Grande L, de Libero C, Mori F, Barni S, et al. Tacrolimus vs. cyclosporine eyedrops in severe cyclosporine-resistant vernal keratoconjunctivitis: A randomized, comparative, double-blind, crossover study. Pediatric Allergy and Immunology. 2015 May 1;26(3):256-61.

13. Taddio A, Cimaz R, Caputo R, de Libero C, Di Grande L, Simonini G, et al. Childhood chronic anterior uveitis associated with vernal keratoconjunctivitis (VKC): Successful treatment with topical tacrolimus. Case series. Pediatric Rheumatology. 2011 Nov 2;9(1).

14. Pucci N, Novembre E, Cianferoni A, Lombardi E, Bernardini R, Caputo R, et al. Efficacy and safety of cyclosporine eyedrops in vernal keratoconjunctivitis. Annals of Allergy, Asthma and Immunology. 2002 Sep 1;89(3):298-303.

15. Zhao M, He F, Yang Y, Lin W, Qiu W, Meng Q, et al. Therapeutic efficacy of tacrolimus in vernal keratoconjunctivitis: A meta-analysis of randomised controlled trials [Internet]. European Journal of Hospital Pharmacy. BMJ Publishing Group; 2020 [cited 2021 Apr 28]. Available from: https://pubmed.ncbi.nlm.nih.gov/33144336/.

16. Nebbioso M, Alisi L, Giovannetti F, Lambiase MAA. Eye drop emulsion containing $0.1 \%$ cyclosporin ( 1 $\mathrm{mg} / \mathrm{mL}$ ) for the treatment of severe vernal keratoconjunctivitis: An evidence-based review and place in therapy [Internet]. Vol. 13, Clinical Ophthalmology. Dove Medical Press Ltd; 2019 [cited 2021 Apr 28]. p. 1147-55. Available from: https://pubmed.ncbi.nlm.nih.gov/31308622/.

17. Supino M, d'Onofrio A, Luongo F, Occhipinti G, Dal Co A. The effects of containment measures in the Italian outbreak of COVID-19. BMC Public Health [Internet]. 2020 Dec 1 [cited 2021 Apr 28];20(1). Available from: https://pubmed.ncbi.nlm.nih.gov/33243199/.

18. Bleik JH, Tabbara KF. Topical Cyclosporine in Vernal Keratoconjunctivitis. Ophthalmology. 1991;98(11):1679-84.

19. Leonardi A, Fauquert JL, Doan S, Delgado L, Andant N, Klimek L, et al. Managing ocular allergy in the time of COVID-19 [Internet]. Vol. 75, Allergy: European Journal of Allergy and Clinical Immunology. Blackwell Publishing Ltd; 2020 [cited 2021 Apr 28]. p. 2399-402. Available from: https://pubmed.ncbi.nlm.nih.gov/32402114/.

20. Brindisi G, de Vittori V, de Castro G, Duse M, Zicari AM. Pills to think about in allergic rhinitis children during COVID-19 era. Acta Paediatrica, International Journal of Paediatrics [Internet]. 2020 Oct 1 [cited 2021 Apr 28];109(10):2149-50. Available from: https://pubmed.ncbi.nlm.nih.gov/32627237/.

21. Cardinale F, Ciprandi G, Barberi S, Bernardini R, Caffarelli C, Calvani M, et al. Consensus statement of the Italian society of pediatric allergy and immunology for the pragmatic management of children 
and adolescents with allergic or immunological diseases during the COVID-19 pandemic [Internet]. Vol. 46, Italian Journal of Pediatrics. BioMed Central; 2020 [cited 2021 Jun 6]. Available from: https://pubmed.ncbi.nlm.nih.gov/32546234/.

22. Montag C, Elhai JD. Discussing digital technology overuse in children and adolescents during the COVID-19 pandemic and beyond: On the importance of considering Affective Neuroscience Theory [Internet]. Vol. 12, Addictive Behaviors Reports. Elsevier Ltd; 2020 [cited 2021 Apr 28]. Available from: https://pubmed.ncbi.nlm.nih.gov/33364321/.

23. Ferreli F, Gaino F, Russo E, di Bari M, Pirola F, Costantino A, et al. Clinical presentation at the onset of COVID-19 and allergic rhinoconjunctivitis. Journal of Allergy and Clinical Immunology: In Practice [Internet]. 2020 Nov 1 [cited 2021 Apr 28];8(10):3587-9. Available from: https://pubmed.ncbi.nlm.nih.gov/32818700/.

24. Al-Dairi W, al Saeed AA, al Sowayigh OM. Impact of Quarantine During COVID-19 Pandemic on the Quality of Life of Patients with Allergic Conjunctivitis. Cureus [Internet]. 2020 Dec 23 [cited 2021 Apr 28];12(12). Available from: https://pubmed.ncbi.nlm.nih.gov/33505811/.

25. Leonardi A, Silva D, Perez Formigo D, Bozkurt B, Sharma V, Allegri P, et al. Management of ocular allergy. Allergy: European Journal of Allergy and Clinical Immunology [Internet]. 2019 Sep 1 [cited 2021 Apr 28];74(9):1611-30. Available from: https://pubmed.ncbi.nlm.nih.gov/30887530/.

26. Leonardi A, Fauquert JL, Doan S, Delgado L, Andant N, Klimek L, et al. Managing ocular allergy in the time of COVID-19 [Internet]. Vol. 75, Allergy: European Journal of Allergy and Clinical Immunology. Blackwell Publishing Ltd; 2020 [cited 2021 Apr 28]. p. 2399-402. Available from: https://pubmed.ncbi.nlm.nih.gov/32402114/.

\section{Figures}




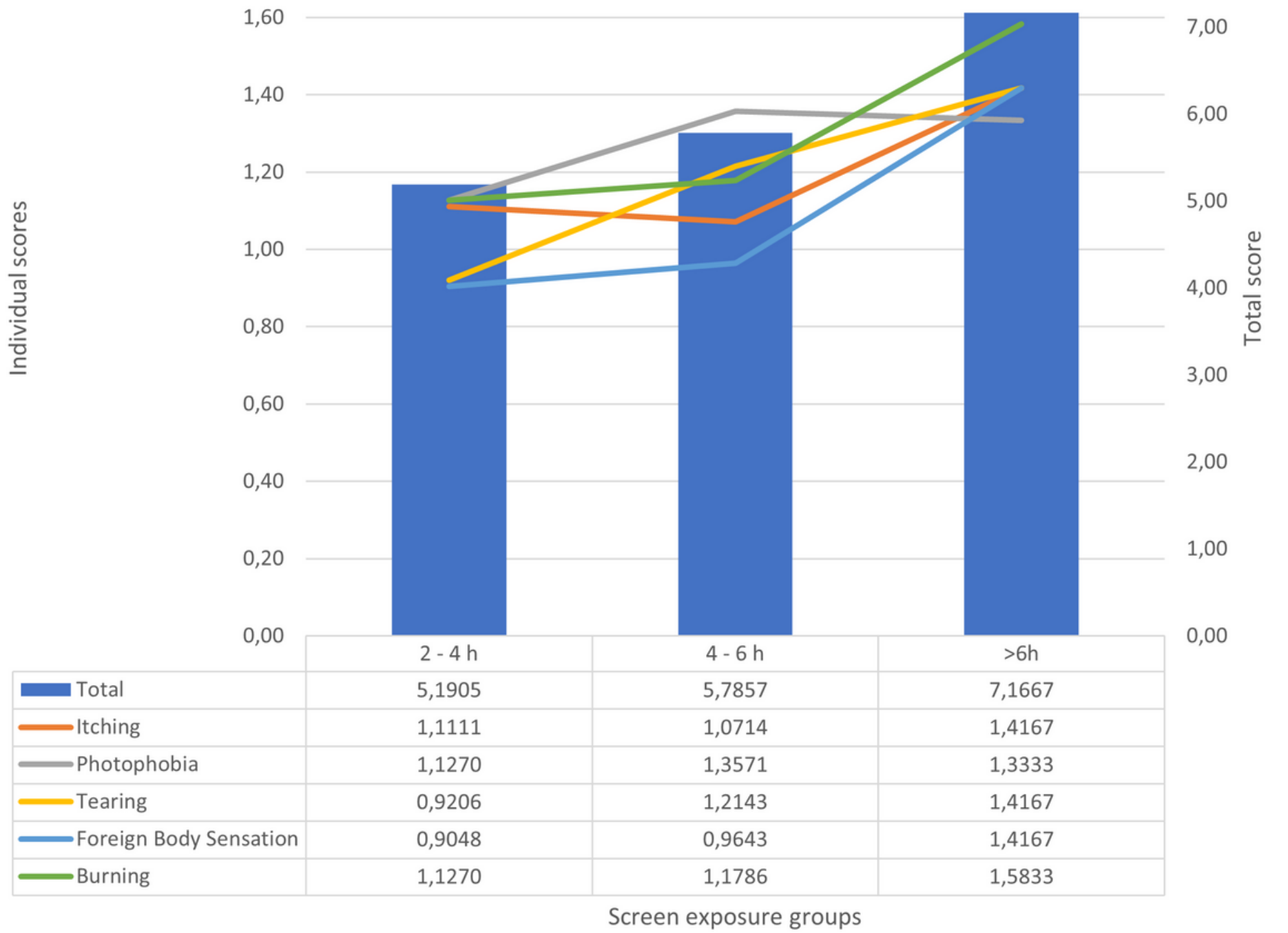

Total Itching Photophobia Tearing Foreign Body Sensation —Burning

\section{Figure 1}

bar graph and table comparing individual and total symptom scores across groups of screen exposure. 